\title{
A Sensitive Assay System for Determination of the Ichthyotoxicity of Prymnesium parvum
}

\author{
By S. ULITZUR AND M. SHILO \\ Department of Microbiological Chemistry, The Hebrew \\ University-Hadassah Medical School, Jerusalem, Israel
}

(Received 11 September 1963)

\begin{abstract}
SUMMARY
The activity of Prymnesium parvum ichthyotoxin and its dependence on various cofactors has been studied. Spermine or other polyamines have a marked synergistic effect on the ichthyotoxic activity. Of the cations studied, $\mathrm{Ca}^{2+}$ and $\mathrm{Mg}^{2+}$ increased ichthyotoxic activity, while $\mathrm{Na}^{+}$ inhibited. Changes in $\mathrm{pH}$ value had a profound influence, ichthyotoxicity increasing at least 400 -fold as the $\mathrm{pH}$ value was increased from 7 to 9 . A sensitive bioassay for the estimation of $\boldsymbol{P}$. parvum ichthyotoxin has been developed for use in the laboratory and under field conditions.
\end{abstract}

\section{INTRODUCTION}

Prymnesium parvum, a halophilic Chrysomonad, has been the cause of extensive fish mortalities in many parts of the world (Shilo, 1964). This organism produces a number of soluble toxic principles including an ichthyotoxin, a haemolysin and a cytotoxin (Otterstrøm \& Steeman-Nielson, 1940; Shilo \& Rosenberger, 1960; Yariv \& Hestrin, 1961). In spite of its widespread endemic occurrence in Israel in brackish water fish ponds, mortality of fish due to $\boldsymbol{P}$. parvum intoxication is observed only sporadically. It has been postulated that the lack of correlation between numbers of phytoflagellates and the toxicity of the pond water was due to a dynamic state of equilibrium existing between toxin formation and destruction (Shilo \& Aschner, 1953), since the ichthyotoxin is readily adsorbed on various colloids and inactivated by external factors such as light (Parnas, Reich \& Bergmann, 1962), heat, high $\mathrm{pH}$ value or by the action of various bacteria (Shilo \& Aschner, 1953). It was further shown that the expression of ichthyotoxic activity was dependent on the presence of cationic cofactors such as $\mathrm{Ca}^{2+}, \mathrm{Mg}^{2+}$ or streptomycin (Yariv \& Hestrin, 1961). The lability of the ichthyotoxin and its cofactor requirements pose special problems in its quantitative estimation. The present paper deals with the effect of different factors on fish toxicity and with the development of a sensitive bioassay for ichthyotoxin estimation.

\section{METHODS}

Chemicals. The chemicals used were obtained from the following sources: streptomycin sulphate (Merck and Co., U.S.A.); spermine tetrahydrochloride and propane-1,3-diamine (Fluka AG. Buchs SG Switzerland); neomycin sulphate (Uclaf, Paris, France); 3,3-diaminodipropylamine (Eastman Kodak Co., U.S.A.); diethyl-

Vol. 86, No. 1 was issued 25 September 1964 
enetriamine, triethylenetetramine, tetraethylenepentamine (L. Light and Co., Ltd., England); putrescine dihydrochloride and cadavarine dihydrochloride (Nutritional Biochemicals Corp., U.S.A.); spermidine trihydrochloride (California Corp. for Biochemical Research, U.S.A.).

Prymnesium parvum culture. The strain of $\boldsymbol{P}$. parvum used in these experiments had been isolated from brackish-water fish ponds in Israel by Reich \& Kahn (1954).

Medium and conditions of growth. The growth medium for Prymnesium parvum used in this work was the defined medium developed by Droop (1958) in which the amounts of trace elements were modified as follows (per litre medium): $\mathrm{FeCl}_{3}$, $5 \mathrm{mg}$.; $\mathrm{MnCl}_{3}, 500 \mu \mathrm{g}$.; $\mathrm{ZnSO}_{4}, 50 \mu \mathrm{g}$.; $\mathrm{CaSO}_{4}, 50 \mu \mathrm{g}$.; $\mathrm{CoSO}_{4}, 5 \mu \mathrm{g}$. $\mathrm{Na}_{2} \mathrm{MoO}_{4} .2 \mathrm{H}_{2} \mathrm{O}$, $5 \mu \mathrm{g}$. The medium was sterilized by autoclaving at $120^{\circ}$ for $20 \mathrm{~min}$. Cultures were grown in Erlenmeyer flasks of $250 \mathrm{ml}$. capacity containing $100 \mathrm{ml}$. liquid medium in continuous 'fluorescent white' daylight, 220-260 foot-candles, at 26-28'. Cultures were harvested after a period of 30-40 days of cultivation.

Extraction and assay of ichthyotoxin. The ichthyotoxin produced by Prymnesium parvum was extracted from the organisms with ethanol as described by Shilo \& Rosenberger (1960). The extraction was facilitated by sonic oscillation (Raytheon sonic oscillator Model DF 101, $10 \mathrm{KC}$ ) for $7 \mathrm{~min}$ at $4^{\circ}$. Such ethanolic extracts were kept at $4^{\circ}$ in the dark and were used in concentrations not exceeding $1 \%$ to avoid toxic effects of the ethanol on the test minnows. For titration of ichthyotoxin two-fold dilutions of the extracts of $\boldsymbol{P}$. parvum were prepared in tris buffer $(0.05 \mathrm{M})$ containing cofactor. In the experiments to be described three minnows $(1 \cdot 5-2 \cdot 0 \mathrm{~cm}$. long) served as test organisms for each dilution. The type and concentration of cofactor were as indicated later and the resulting fish toxicity expressed relative to toxicity under standard conditions of test, as described below in the definition of an ichthyotoxic unit. The $\mathrm{pH}$ value of the test solution was readjusted when necessary every hour with $\mathrm{N}-\mathrm{NaOH}$.

An 'ichthyotoxic unit' of toxin (ITU) was defined as the minimal amount of Prymnesium parvum toxin $/ \mathrm{ml}$. which killed within $8 \mathrm{hr}$ all the fish in the test system containing tris buffer $(0.05 \mathrm{M})$ and spermine $(0.5 \mathrm{mg} . / \mathrm{ml}$.) as cofactor, at $\mathrm{pH} 8.0$ and $25^{\circ}$ in the dark.

\section{RESULTS}

\section{The effect of different cofactors on the ichthyotoxic activity}

Cofactors studied included $\mathrm{Ca}^{2+}, \mathrm{Mg}^{2+}$ and streptomycin, which have been shown by Yariv \& Hestrin (1961) to enhance the activity of Prymnesium parvum ichthyotoxin, and spermine, neomycin and several polyamines. Figure 1 summarizes the results of these experiments. A marked effect of spermine in enhancement of ichthyotoxicity occurred; this was 5 times greater than the enhancement with neomycin and 10 times greater than that observed with $\mathrm{Ca}^{2+}$ or streptomycin when these substances were tested at $0.0045 \mathrm{M}, \mathrm{pH} 8 \cdot 0$. The effect of other amines on the ichthytotoxic activity is summarized in Table 1. Additional materials tested for their synergistic activity as cofactors included lysine, arginine, histamine, ornithine, chloramphenicol, and erythromycin $(0.5 \mathrm{mg} . / \mathrm{ml}$. at $\mathrm{pH} 8.0$ and 9.0$)$. None of these materials showed any cofactor activity except for a slight effect with histamine at $\mathrm{pH} \mathrm{9.0.} \mathrm{A} \mathrm{relationship} \mathrm{was} \mathrm{found} \mathrm{to} \mathrm{exist} \mathrm{between} \mathrm{the} \mathrm{concentration}$ of every one of the active cofactors tested and the minimal lethal dose (MLD) of 
chthyotoxin of $P$. parvum. This relationship, described by Yariv \& Hestrin (1961), can be expressed as cofactor concentration $\times M L D=$ a constant; this held up to a concentration of 0.0035-0.0045 $\mathrm{M}$ for all the cofactors tested. On further increase of cofactor concentration no additional decrease in the minimal lethal dose was observed.

Table 1. The effect of various polyamines on ichthyotoxic activity of Prymnesium parvum

Cofactor used at concentration of $0.0015 \mathrm{M}$

Formula of the cofactor

Relative

Spermine

Spermidine

3,3-Diaminodipro-

pylamine

Diethylene triamine

Triethylene tetramine

Tetraethylene

pentamine

Propane 1,3-diamine

Putrescine

Cadavarine

Without cofactor

$$
\begin{aligned}
& \mathrm{NH}_{2}-\left(\mathrm{CH}_{2}\right)_{3}-\mathrm{NH}-\left(\mathrm{CH}_{2}\right)_{4}-\mathrm{NH}\left(\mathrm{CH}_{2}\right)_{3}-\mathrm{NH}_{2} \\
& \mathrm{NH}_{2}-\left(\mathrm{CH}_{2}\right)_{3}-\mathrm{NH}-\left(\mathrm{CH}_{2}\right)_{4}-\mathrm{NH}_{2} \\
& \mathrm{NH}_{2}-\left(\mathrm{CH}_{2}\right)_{3}-\mathrm{NH}-\left(\mathrm{CH}_{2}\right)_{3}-\mathrm{NH}_{2} \\
& \mathrm{NH}_{2}-\left(\mathrm{CH}_{2}\right)_{2}-\mathrm{NH}-\left(\mathrm{CH}_{2}\right)_{2}-\mathrm{NH}_{2} \\
& \mathrm{NH}_{2}-\left(\mathrm{CH}_{2}\right)_{2}-\mathrm{NH}-\left(\mathrm{CH}_{2}\right)_{2}-\mathrm{NH}-\left(\mathrm{CH}_{2}\right)_{2}-\mathrm{NH}_{2} \\
& \mathrm{NH}_{2}-\left(\mathrm{CH}_{2}\right)_{2}-\mathrm{NH}-\left(\mathrm{CH}_{2}\right)_{2}-\mathrm{NH}-\left(\mathrm{CH}_{2}\right)_{2}-\mathrm{NH}-\left(\mathrm{CH}_{2}\right)_{2}-\mathrm{NH}_{2} \\
& \mathrm{NH}_{2}-\left(\mathrm{CH}_{2}\right)_{3}-\mathrm{NH}_{2} \\
& \mathrm{NH}_{2}-\left(\mathrm{CH}_{2}\right)_{4}-\mathrm{NH}_{2} \\
& \mathrm{NH}_{2}-\left(\mathrm{CH}_{2}\right)_{5}-\mathrm{NH}_{2}
\end{aligned}
$$$$
\text { activity }
$$

Titrations were carried out in the dark at $28^{\circ}$, in $0.05 \mathrm{~m}$ tris buffer at $\mathrm{pH} 8.0$. Results were recorded after $4 \mathrm{hr}$. The toxin employed was ' $\mathrm{S}$ ' extract having $4000 \mathrm{ITU} / \mathrm{ml}$. Identical results were obtained in all of the five assays made with each cofactor.

\section{Combined effects of various cofactors on ichthyotoxic activity}

The possibility that more than one cofactor may be active in the natural environment of the fish led us to investigate the effect of combining different cofactors. Experiments on the effect of increasing concentrations of $\mathrm{CaCl}_{2}$, in presence or absence of spermine, on the ichthyotoxic activity are summarized in Fig. 2. It can be seen that with increasing concentrations of $\mathrm{Ca}^{2+}$, the ichthyotoxicity in the presence of spermine decreased rapidly and approached the value obtained with $\mathrm{Ca}^{2+}$ alone. The overall cofactor activity of the $\mathrm{Ca}^{2+}$ and spermine mixtures tested on the ichthyotoxicity was found to approach the sum of the activities of the individual cofactors in the mixture each multiplied by its relative concentration (expressed as percentage of total molar cofactor concentration) in the system. No difference in final ichthyotoxicity was found between tests of simultaneous addition of spermine and $\mathrm{Ca}^{2+}$ and tests where one of the cofactors was added $30 \mathrm{~min}$. before adding the other.

The study of the effect of increasing concentrations of $\mathrm{Ca}^{2+}$ on ichthyotoxicity in presence of a constant concentration of streptomycin $(0.001 \mathrm{M})$ as cofactor showed (Fig. 3) an increase in ichthyotoxicity up to $0.003 \mathrm{M}-\mathrm{Ca}^{2+}$, a concentration at which the maximal effect is obtained when $\mathrm{Ca}^{2+}$ served as the single cofactor.

The effect of increasing concentrations of different salts $(\mathrm{NaCl}$; sea water; $\mathrm{NaCl}+\mathrm{CaCl}_{2}$ in a ratio of $26: 1$ as found in sea water; brackish pond water) and of different concentrations of sucrose on the ichthyotoxicity of Prymnesium parvum extracts was studied. Results of a typical experiment in presence and absence of spermine are summarized in Fig. 4 . It can be seen that with increasing $\mathrm{NaCl}$ con- 


\section{4 \\ S. Ulitzur AND M. ShILO}

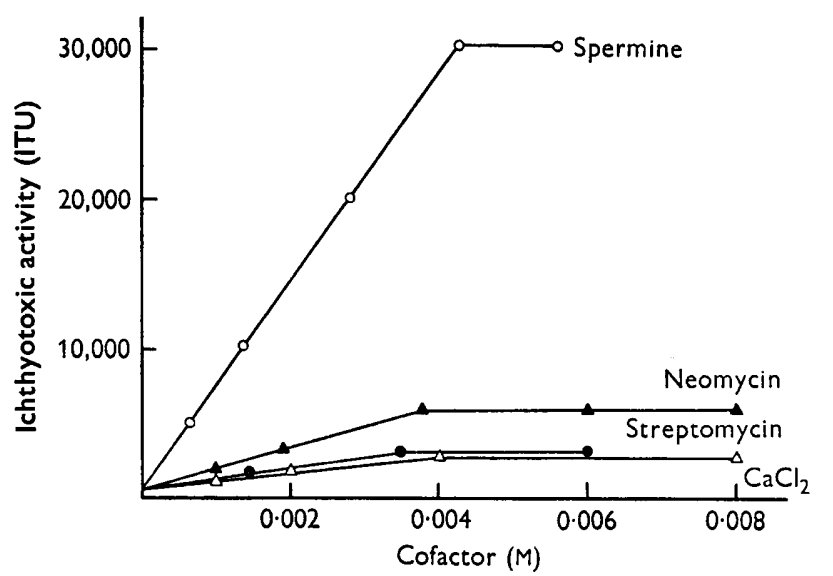

Fig. 1

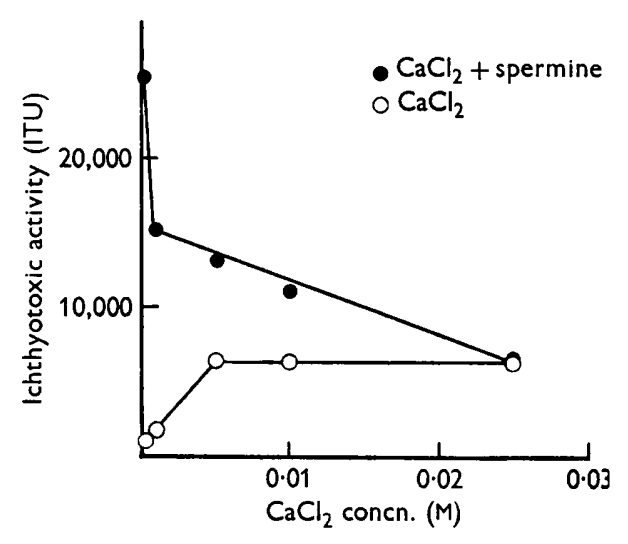

Fig. 2

Fig. 1. The effect of concentration of spermine, neomycin, $\mathrm{CaCl}_{2}$ and streptomycin on activity of Prymnesium paroum ichthyotoxin. Titrations were carried out in the dark at $25^{\circ}$ with tris buffer (pH 8.0). Results were recorded after $8 \mathrm{hr}$. The toxin used was extract ' $\mathrm{S}$ ' having $10,000 \mathrm{ITU} / \mathrm{ml}$.

Fig. 2. The combined effect of spermine and $\mathrm{CaCl}_{2}$ on activity of Prymnesium parvum ichthyotoxin. Tests were carried out at $\mathrm{pH} \mathrm{9.0} \mathrm{in} 0 \cdot 05 \mathrm{M}$-tris buffer. Solutions contained various concentrations of $\mathrm{CaCl}_{2}$ and a constant concentration of spermine $(0 \cdot 0014 \mathrm{M})$. Control solutions contained various $\mathrm{CaCl}_{2}$ concentrations only in $0.05 \mathrm{M}$-tris buffer ( $\mathrm{pH}$ 9.0). Tests were carried out at $25^{\circ}$ in the dark. Results were recorded after $8 \mathrm{hr}$. Extract ' $\mathrm{S}$ ' having activity $6400 \mathrm{ITU} / \mathrm{ml}$. was used.

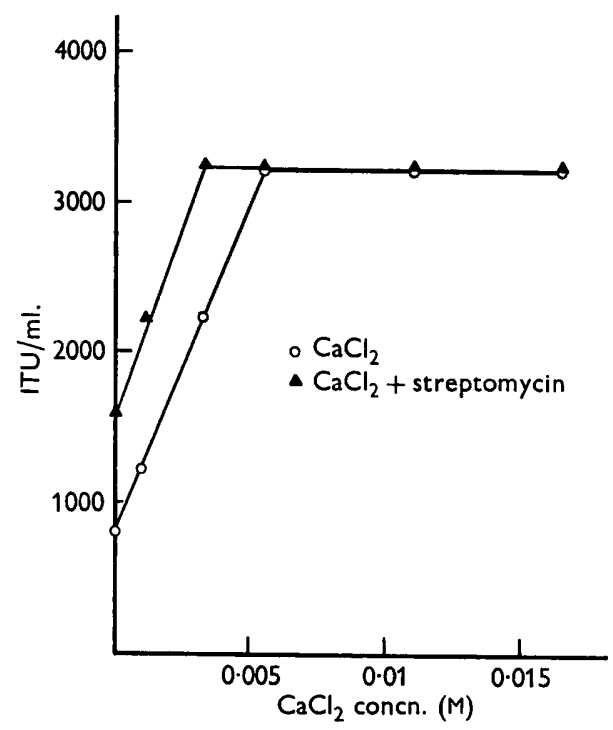

Fig. 3. The combined effect of streptomycin and $\mathrm{CaCl}_{2}$ on activity of Prymnesium parvum ichthyotoxin. Tests were made at $\mathrm{pH} 8.0$ in $0.05 \mathrm{M}$-tris buffer solutions containing various concentrations of $\mathrm{CaCl}_{2}$ and a constant concentration of streptomycin $0.001 \mathrm{M}$. Control solutions contained various $\mathrm{CaCl}_{2}$ concentrations only, in $0.05 \mathrm{M}$-tris buffer (pH 8.0). Tests were carried out at $25^{\circ}$ in the dark. Results were recorded after $8 \mathrm{hr}$. Extract ' $\mathrm{S}$ ' of activity $12,800 \mathrm{ITU} / \mathrm{ml}$. was used. 
centrations up to $3.0 \mathrm{mg}$. $\mathrm{Cl}-/ \mathrm{ml}$. or with equivalent salt concentrations in sea or pond water, there was a marked decrease of ichthyotoxic activity in the presence of spermine and a slight decrease in its absence. With further increase in salt concentration a progressive increase in ichthyotoxic activity independent of the presence of spermine was observed.

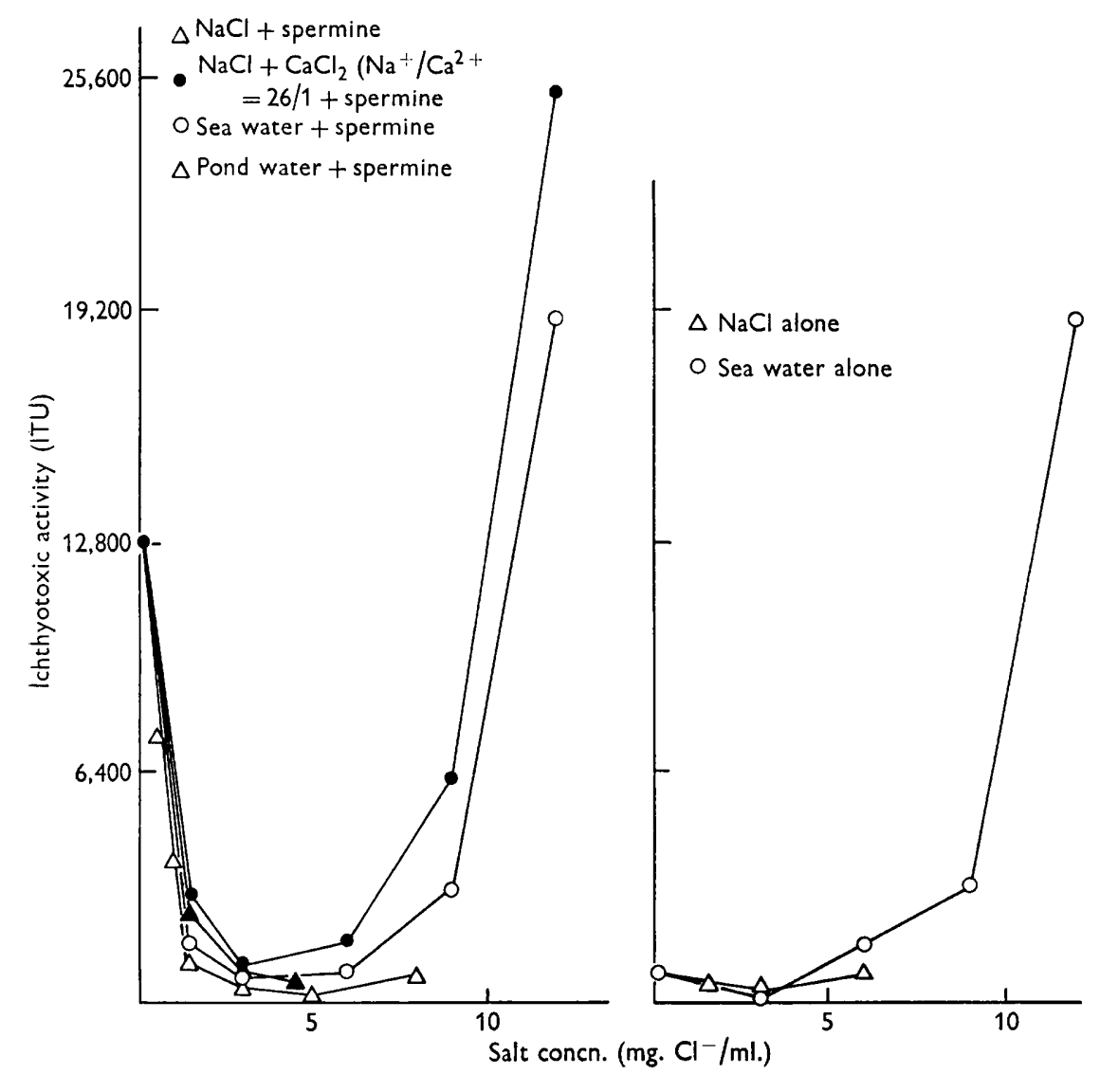

Fig. 4. Effect of various salt concentrations on activity of Prymnesium parvum ichthyotoxin. Tests were carried out at $\mathrm{pH} 8.0$ in $0.05 \mathrm{M}$-tris buffer in the dark; results were recorded after $8 \mathrm{hr}$ at $25^{\circ}$. Concentration of spermine was $0.5 \mathrm{mg} . / \mathrm{ml}$. (0.0014 M); $\mathrm{NaCl}$ concentration is expressed as $\mathrm{mg}$. $\mathrm{Cl}-/ \mathrm{ml}$. The toxin used was extract ' $\mathrm{S}$ ' of activity 12,800 ITU/ml.

The inhibitory effect of different salt concentrations on the ichthyotoxic activity was reversible. Toxic solutions dissolved in $15 \%(\mathrm{v} / \mathrm{v})$ sea water diluted in distilled water, a concentration at which $98 \%$ of the activity observed in the absence of salt was suppressed, was rendered fully toxic by dialysis for $20 \mathrm{hr}$ against distilled water.

In experiments with streptomycin $+\mathrm{Ca}^{2+}$ as cofactors, increasing amounts of $\mathrm{NaCl}$ up to $3.0 \mathrm{mg}$. $\mathrm{Cl}-/ \mathrm{ml}$. caused a progressive inhibition of the ichthyotoxicity, similar to that observed with spermine. Addition of sucrose up to $0.2 \mathrm{M}$ did not 
affect the activity of ichthyotoxin in presence of spermine, thus excluding the possibility that the suppression of ichthyotoxic activity by different salts was caused by increased osmotic pressure of the suspension medium.

\section{The effect of $p H$ value on the activity of Prymnesium parvum ichthyotoxin}

Experiments on the effect of the $\mathrm{pH}$ value of the medium on the activity of ichthyotoxin in the presence or absence of added cofactors are summarized in Table 2. An increase in ichthyotoxicity was observed with an increase in $\mathrm{pH}$ value of the test medium with all the cofactors studied, and even in the absence of added cofactor. The activity at $\mathrm{pH} \mathrm{9.0} \mathrm{was} \mathrm{four} \mathrm{times} \mathrm{greater} \mathrm{than} \mathrm{that} \mathrm{at} \mathrm{pH} 8.0$; no ichthyotoxic activity was observed in the system at $\mathrm{pH} \mathbf{7 \cdot 0}$.

\section{Table 2. The effect of $p H$ on ichthyotoxic activity}

$\begin{array}{lccc}\begin{array}{l}\text { Cofactor used at con- } \\ \text { centration of 0.0015 }\end{array} & \begin{array}{c}\text { Activity at } \\ \text { pH 7.0 }\end{array} & \begin{array}{c}\text { Activity at } \\ \text { pH 8.0 }\end{array} & \begin{array}{c}\text { Activity at } \\ \text { pH 9.0 }\end{array} \\ \text { CaCl }_{2} & <100 & 1000 & 4000 \\ \text { Streptomycin } & <100 & 1000 & 4000 \\ \text { Spermine } & <100 & 10 \cdot 000 & 40 \cdot 000 \\ \text { 3,3-Diaminodipropylamine } & <100 & 5000 & 20 \cdot 000 \\ \text { Neomycin } & <100 & 2000 & 4000 \\ \text { Without cofactor } & <100 & 250 & 1000\end{array}$

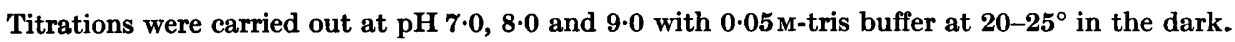
Results were recorded after $8 \mathrm{hr}$. Identical results were obtained in all of the five assays made with each cofactor.

\section{The effect of temperature on the ichthyotoxic activity of Prymnesium parvum}

The effect of temperature in the range of $10-30^{\circ}$ at $\mathrm{pH} \mathrm{8.0}$ on the killing of minnows by Prymnesium parvum ichthyotoxin in the presence of spermine is shown in Fig. 5. It can be seen from this figure that an increase in temperature caused an increase in the rate of mortality but did not affect the final titre (MLD) of the toxin. Experiments at $\mathrm{pH} 9 \cdot 0$ showed a similar effect of temperature on the kinetics of killing, but the rate was $30-50 \%$ greater than that observed at $\mathrm{pH} 8 \cdot 0$. Temperatures higher than $30^{\circ}$ were not tolerated by the fish under the test conditions.

\section{ASSAY OF ICHTHYOTOXIN}

On the basis of the experiments reported above we have developed the following test for assaying the ichthyotoxin produced by Prymnesium parvum. The procedure is essentially the same as described under Methods, with $0.5 \mathrm{mg}$. spermine/ $\mathrm{ml}$. as a cofactor and tris buffer $(0.05 \mathrm{M})$ adjusted to $\mathrm{pH} \mathrm{9.0} \mathrm{with} \mathrm{HCl}$. The titration, with three standard size minnows for each test condition, is carried out at 26-28 ${ }^{\circ}$ in the dark, and the results recorded after $3 \mathrm{hr}$. In cases where the samples tested contain high concentration of salt (e.g. brackish pond water or growth media of $\boldsymbol{P}$. parvum) the medium is dialysed against distilled water for several hours before the test. An examination of the reproducibility of this test under the standard conditions at $\mathrm{pH} 8$ and 9 showed the results to be highly dependable with a standard deviation ranging from 10 to $30 \%$. 


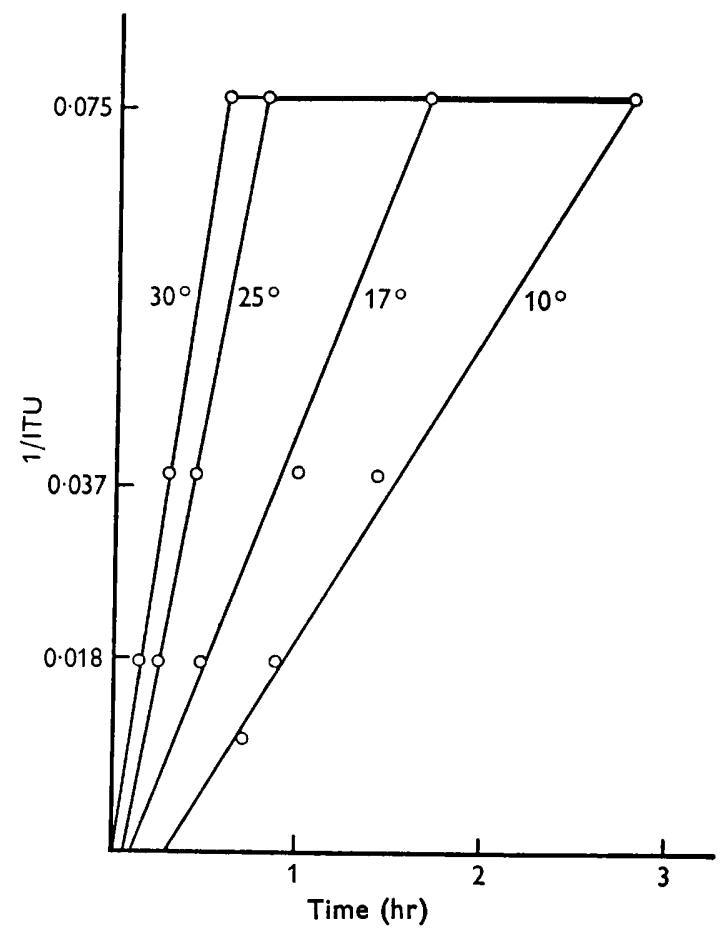

Fig. 5. The effect of temperature on activity at pH 8.0 of Prymnesium paroum ichthyotoxin. Tests were carried out at $\mathrm{pH} 8.0$ in $0.05 \mathrm{M}$-tris buffer + spermine $0.0014 \mathrm{M}$ in the dark. The minnows were incubated in tap water for $12 \mathrm{hr}$ before test at temperatures corresponding to those used in the tests. Average time for loss of equilibrium of all three minnows was recorded. Control fish remained unaffected for $\mathbf{3} \mathbf{~ h r}$ after the death of all test fishes. Extract ' $S$ ' having 12,800 ITU/ml. was used in these tests.

\section{DISCUSSION}

The present study confirms and extends the findings of Yariv \& Hestrin (1961) on the cofactor requirements of Prymnesium parvum ichthyotoxin. In addition to $\mathrm{Ca}^{2+}, \mathrm{Mg}^{2+}$ and streptomycin described by these workers, other cationic substances, e.g. neomycin, spermine and certain other polyamines, were shown to enhance the ichthyotoxicity of $\boldsymbol{P}$. parvum extract. All the compounds so far found to have cofactor activity in the $\boldsymbol{P}$. parvum ichthyotoxic system have been reported to act as stabilizing agents in a variety of biological systems such as bacterial spheroplasts and protoplasts, mitochondria and microsomes (Tabor, Tabor \& Rosenthal, 1961); in all these systems, spermine was the most active.

It has been confirmed that the quantitative relationship between cofactor and ichthyotoxin expressed by Yariv \& Hestrin (1961) as $a \times b=Q$ (where $a$ is the ichthyotoxin concentration, $b$ the minimum concentration of cofactor which elicits a lethal effect in presence of $a$, and $Q$ is a cofactor-specific constant) holds for all the cofactors tested, but that this relationship has an upper limit at cofactor concentration of $0.0045 \mathrm{M}$.

In the presence of more than one cofactor the resulting toxicity is not necessarily additive but depends on the specific activity of each cofactor and its concentration relative to the other cofactor. Thus, the addition of a cofactor of low activity, e.g. 
$\mathrm{Ca}^{2+}$, to a system containing a cofactor of high activity, e.g. spermine, drastically lowers the degree of toxicity to fish. On the other hand, the addition of $\mathrm{Ca}^{2+}$ to a system containing a limiting concentration of streptomycin (a cofactor of roughly equivalent activity) increases fish toxicity. This has the result that in high concentrations of $\mathrm{Ca}^{2+}$ the effects of spermine and streptomycin are masked. This relationship and the phenomenon of cofactor saturation might be due to competition of cofactors for similar sites.

It has already been emphasized (Shilo \& Aschner, 1953) that no correlation was found between the population density of Prymnesium parvum in brackish fish ponds and the concentration of ichthyotoxin in the water. It has been suggested that this phenomenon can be explained partly through the continuous destruction of excreted toxin by various inactivating factors. The present findings on the effects of $\mathrm{pH}$ value, salt concentration and temperature on the activity of the ichthyotoxin show that various environmental factors may in this manner play a decisive role in determining the overall picture of toxicity. In fact, a survey of the appearance of fish intoxication in brackish-water fish ponds in Israel has shown that a correlation exists between toxicity and elevated $\mathrm{pH}$ values and/or low salinity of pond water. Furthermore, the widely differing activity of the various cofactors tested, such as $\mathrm{Ca}^{2+}$, streptomycin and some polyamines, in enhancing ichthyotoxicity suggests that the concentration and nature of cofactor or cofactors in the milieu may have a profound influence on final toxic effect of $\boldsymbol{P}$. parvum in a pond or culture.

The bioassay for the ichthyotoxin developed was suitable for the determination of extracellular, as well as intracellular ichthyotoxin from axenic cultures and from Prymnesium parvum blooms in fish ponds. By using this assay method it was possible to detect sublethal amounts of ichthyotoxin in ponds (as low as $\sim 1 / 30$ of the lethal dose for carp). Since only a small percentage of Prymnesium-infested ponds in nature develop lethal concentrations of ichthyotoxin, this method has economic importance since it limits the need for control of the phytoflagellate to those ponds containing detectable sublethal amounts of toxin.

This work was supported by a grant from the Ford Foundation.

We are indebted to Dr R.F. Rosenberger and to Dr U. Bachrach for helpful suggestions concerning the manuscript and to S. Sarig, M. Lahav and G. Vardina of Nir David for their help in the field experiments.

\section{REFERENCES}

Droop, M. R. (1958). Requirement for thiamine among some marine and supra-littoral protista. J. Mar. biol. Ass. U.K. 37, 323.

OtTerstrøa, C. V. \& Steemann-Nielson, E. (1940). Two cases of extensive mortality in fishes caused by flagellate Prymnesium parvum Carter. Rep. Danish biol. Sta., Copenhagen, 44, 5 .

Parnas, I., Reich, K. \& Bergmann, F. (1962). Photoinactivation of ichthyotoxin from axenic cultures of Prymnesium paroum Carter. Appl. Microbiol. 10, 237.

REICH, K. \& KaHn, J. (1954). A bacteria-free culture of Prymnesium parvum (Chrysomonidiae). Bull. Res. Coun. Israel, $5,114$.

Shilo, M. \& Aschner, M. (1953). Factors governing the toxicity of cultures containing the phytoflagellate Prymnesium parvum Carter. J. gen. Microbiol. 8, 333. 
Shilo, M. \& Rosenberger, R. F. (1960). Studies on the toxic principles formed by the Chrysomonad Prymnesium parvum Carter. Ann. N.Y. Acad. Sci. 90, 866.

Shilo, M. (1964). Review of toxigenic algae. Proc. int. Ass. theor. appl. Limnology, p. 15.

Tabor, H., Tabor, C. W. \& Rosenthal, S. (1961). The biochemistry of the polyamines spermidine and spermine. Annu. Rev. Biochem. 30, 579.

YARIv, J. \& Hestrin, S. (1961). Toxicity of the extracellular phase of Prymnesium paroum cultures. J. gen. Microbiol. 24, 165. 